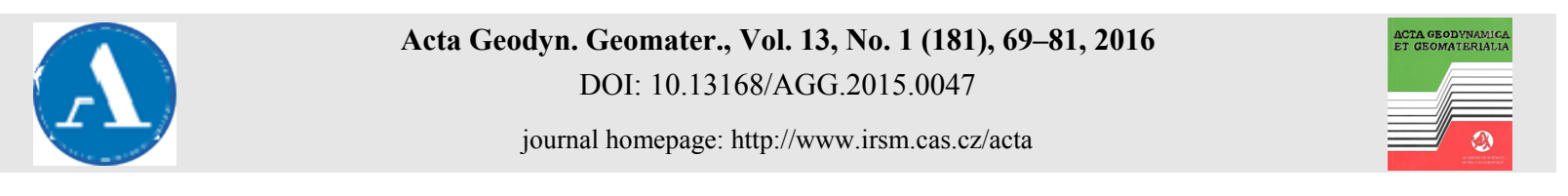

ORIGINAL PAPER

\title{
GPS/GLONASS PRECISE POINT POSITIONING WITH IGS REAL-TIME SERVICE PRODUCTS
}

\author{
Grzegorz KRZAN * and Pawel PRZESTRZELSKI
}

University of Warmia and Mazury in Olsztyn, Oczapowskiego 2, 10-719 Olsztyn, Poland

*Corresponding author's e-mail: grzegorz.krzan@uwm.edu.pl

\begin{tabular}{l} 
ARTICLE INFO \\
\hline Article history: \\
Received 20 April 2015 \\
Accepted 16 September 2015 \\
Available online 7 October 2015 \\
\hline
\end{tabular}

Keywords:

Real-time PPP

IGS RTS

GPS

GLONASS

\begin{abstract}
The International GNSS Service (IGS) in April 2013 started real-time services (IGS-RTS) to provide access to high-precision products such as orbits, clocks and code observation errors. Products containing corrections are delivered to users by the RTCM data stream in real-time. The IGS03 stream which contains corrections for GPS and GLONASS systems is currently in the experimental stage and positioning with its use is still insufficiently investigated in terms of accuracy and reliability of positioning.

In this paper we evaluate the impact of the IGS-RTS streams on positioning. In research section we presented the results of the processing of two-week satellite observations registered at five IGS stations located at different latitudes, using the three IGS-RTS streams: IGS01, IGS02 and IGS03, and BKG Ntrip Client (BNC). Post-processing involved the utilization of GPS and GPS+GLONASS signals. Subsequently we analyzed the real-time position determination of MARS IGS station using IGS03 data stream, which showed one of the best performance during the development of observation in post-processing mode. In analysis we applied approach showing the probability of achieving results within the assumed ranges of accuracy $(<1.0 \mathrm{~m}$, $<0.5 \mathrm{~m},<0.2 \mathrm{~m},<0.1 \mathrm{~m})$. This approach allows the estimation of potential applications, depending on the expected accuracy of positioning.
\end{abstract}

\section{INTRODUCTION}

Global Navigation Satellite Systems (GNSS) are used in many areas of our everyday life, not only in navigation, as its acronym states, but also in applications requiring the highest accuracy, such as surveying, deformation monitoring and atmospheric research (Bakuła, 2013; Wielgosz et al., 2013; Baryła et al., 2014). Among all of the known precise GNSS positioning strategies two groups can be distinguished: differenced and un-differenced. The former method includes relative positioning strategy, e.g. Real Time Kinematic (RTK). In this case the process of coordinate estimation requires at least two (or more) receivers operating simultaneously. Observation differences (single, double and triple) formulated between receivers and satellites serve to eliminate or mitigate many biases associated with GNSS positioning (Misra and Enge, 2011). To achieve the highest accuracy satellite measurements are usually conducted in unobstructed areas. However the use of an appropriate surveying technology can obtain centimeter-level accuracy even in environments with a high degree of difficulty for satellite access (Bakuła et al., 2015). Nevertheless, in both cases users are limited by the distance to the closest reference station. To overcome this issue the un-differenced positioning strategies are being developed, and one of widely researched is the Precise Point Positioning
(PPP) strategy. It does not require a direct set of observations from a single station or station network, but instead needs high quality external corrections.

Over the last decade, the PPP has proven to be a very useful tool and found application in various fields (e.g. monitoring of reference stations, time and frequency transfer or signal analysis (Zumberge et al., 1997; Defraigne et al., 2007; Chen et al., 2009; Leandro et al., 2011)). For this reason, it has been investigated by scientists all around the world. Various research facilities have investigated PPP performance using their own applications or opensource projects (Salazar et al., 2010; Laurichesse, 2011; Li et al., 2013). On the internet one can find automatic services enabling position estimation in the PPP mode (Dawidowicz et al., 2014). Currently, PPP is conducted mainly with GPS, but other satellite navigation systems are being included into the process of position estimation, i.e. GLONASS, Galileo, BeiDou (Juan et al., 2012; Cai and Gao, 2013; Li et al., 2013). The main challenge of PPP is still that it typically requires about $30 \mathrm{~min}$ to obtain centimeterlevel accuracy or to succeed in the first ambiguityfixing (Li and Zhang, 2014).

In most cases dual frequency code and carrier phase observations and ionosphere-free combination are utilized to obtain precise coordinates. Thus, ionospheric delays are not taken into consideration, 
Table 1 Centimeter-level corrections for un-differenced point positioning.

\begin{tabular}{ll}
\hline Correction & Approximate value* \\
\hline Solid Earth Tides & $<30 \mathrm{~cm}$ in the radial and \\
& $<5 \mathrm{~cm}$ in the horizontal direction \\
Ocean Loading** & $<5 \mathrm{~cm}$ in the radial and \\
& $<2 \mathrm{~cm}$ in the horizontal directions \\
Earth Rotation Parameters (ERP) & $\sim 3 \mathrm{~cm}$ on the Earth surface \\
Polar Tides & $<25 \mathrm{~cm}$ in the height and \\
& $<07 \mathrm{~cm}$ in the horizontal directions \\
Atmospheric Loading** & typically $\sim 3-5 \mathrm{~mm}$ \\
Phase Windup & $<$ one half of the wavelength \\
Satellite Antenna Phase Center Offsets & depends on the antenna model \\
\hline Satellite Antenna Phase Center Variations & \\
Receiver Antenna Offset & \\
Receiver Antenna Phase Center Variations & \\
\hline
\end{tabular}

* approximate values are given based on vanDam et al. (1994) and Kouba (2009)

** for coastal stations.

Table 2 IGS-RTS streams and their description.

\begin{tabular}{lllll}
\hline Stream name & Combination type & Ref. point & $\begin{array}{c}\text { Transmitted RTCM } \\
\text { Messages (sample } \\
\text { interval in seconds) }\end{array}$ & Supported systems \\
\hline IGS01 & Single-Epoch & APC & $1059(5), 1060(5)$ & GPS \\
IGC01 & Single-Epoch & CoM & $1059(5), 1060(5)$ & GPS \\
IGS02 & Kalman Filter & APC & $1057(60), 1058(10)$, & GPS \\
& Kalman Filter & APC & $1059(10)$ & GPS, GLONASS \\
IGS03 & & $1057(60), 1058(10)$, & \\
& & & $1059(10), 1063(60)$, & \\
\hline
\end{tabular}

but PPP still requires precise satellite orbits and clocks, and estimation of tropospheric delays. The other centimeter-level corrections along with their approximate values commonly used to achieve the highest accuracy using PPP are provided in Table 1.

The magnitude of the corrections given in Table 1 is based on van Dam et al. (1994) and Kouba (2009). The number of different corrections usually forces the use of PPP in post-processing, but scientific progress allows real-time measurements.

Most of real-time PPP studies are made with respect to positioning applications (Douša and Vaclavovič, 2014; Li et al., 2014; Shi et al., 2015). It was shown that real-time GPS PPP provides centimeter precision after the solution convergences (Chen et al., 2013b; Elsobeiey and Al-Harbi, 2015). Li et al. (2015) have demonstrated and evaluated a multiGNSS (GPS, GLONASS, BeiDou, and Galileo) realtime PPP service system based on a predicted orbit and real-time estimated clocks. Multiple GNSS significantly increases the number of observed satellites, optimizes the spatial observation geometry and improves convergence, accuracy, continuity and reliability of real-time GPS PPP positioning (Li et al., 2015).

\section{IGS REAL-TIME SERVICE PRODUCTS}

On the April 1, 2014 the International GNSS Service (IGS) launched the Real-Time Service (RTS) which provides access to real-time precise products (orbits, clocks and code biases) which can be used as a substitute for ultra-rapid products in real-time applications. RTS is based on the IGS global infrastructure of network stations, data centers and analysis centers. A number of research centers participate in this project. The collaboration and data flow between them is presented on the following web page: http://igs.bkg.bund.de/ntrip/ppp. Table 2 lists all available streams of the IGS-RTS.

The official products currently include corrections to the GPS satellite orbits and clocks (IGS01 single-epoch combination and IGS02 Kalman filter combination). The third one, IGS03, containing additional GLONASS corrections is offered as an experimental product. For orbit parametrization purposes user can also utilize IGC01 stream which is a parallel to IGS01 product, referenced to satellites center of mass. For a better understanding of the content of an individual stream, the authors have briefly summarized in Table 3 the most important messages of the RTCM standard (Radio Technical Commission for Maritime) transmitted by IGS-RTS. 
Table 3 Selected RTCM v3 Messages.

\begin{tabular}{ll}
\hline Message type & Description \\
\hline $\mathbf{1 0 5 7}$ & GPS orbit corrections to Broadcast Ephemeris \\
$\mathbf{1 0 5 8}$ & GPS clock corrections to Broadcast Ephemeris \\
$\mathbf{1 0 5 9}$ & GPS code biases \\
$\mathbf{1 0 6 0}$ & Combined orbit and clock corrections to GPS Broadcast Ephemeris \\
$\mathbf{1 0 6 3}$ & GLONASS orbit corrections to Broadcast Ephemeris \\
$\mathbf{1 0 6 4}$ & GLONASS clock corrections to Broadcast Ephemeris \\
$\mathbf{1 0 6 5}$ & GLONASS code biases \\
\hline
\end{tabular}

The IGS-RTS orbits are expressed within the International Terrestrial Reference Frame 2008 (ITRF2008). Orbit corrections are provided as alongtrack, cross-track and radial offsets to the Broadcast Ephemeris in an Earth-centered and Earth-fixed reference frame. After applying corrections, the satellite position is referred to the 'ionosphere-free' phase center of the antenna (for the APC streams) or to the satellite Center of Mass (CoM streams). Clock corrections are given as offsets to the Broadcast Ephemeris satellite clock corrections (http://igs.org/rts/products). Kouba (2009) described precisely the IGS products while Hadaś and Bosy (2014) verified the accuracy and availability of the IGS GPS (>95\%) and GLONASS (>90\%) orbit and clock corrections, and stated that accuracy of the clock corrections degrades faster over time.

Comparing IGS-RTS with ESA/ESOC (European Space Agency/European Space Operation Center) final products the authors confirmed the accuracy of RTS orbits: $48 \mathrm{~mm}$ for GPS and $132 \mathrm{~mm}$ for GLONASS. The real-time clocks accuracy is $84 \mathrm{~mm}$ (i.e. $0.28 \mathrm{~ns}$ ) and $245 \mathrm{~mm}$ (i.e. $0.82 \mathrm{~ns}$ ) for GPS and GLONASS, respectively. Furthermore Hadaś and Bosy (2014) stated that estimation of GLONASS clock corrections require further development. The minimum time required to provide corrections is about $28 \mathrm{~s}$ for IGS01 stream and $31 \mathrm{~s}$ for the IGS03. This difference is caused by the application of the Kalman filter in the IGS03 stream. Hadaś and Bosy (2014) also researched the achievable accuracy during RTS outages and proposed polynomial fitting to extend the validity and accuracy of the corrections.

\section{MATHEMATICAL MODEL}

In order to achieve high positioning accuracy using the PPP, the satellite observations are usually performed by dual-frequency GNSS receivers. The observation equations for code and phase measurements, made at two frequencies, can be written in the following form (Cai and Gao, 2007):

$$
\begin{aligned}
& P=\rho+c(d t-d T)+d_{o r b}+d_{t r p}+d_{i o n}+\varepsilon_{p} \\
& \phi=\rho+c(d t-d T)+d_{o r b}+d_{t r p}-d_{i o n}+\lambda N+\varepsilon_{\phi}
\end{aligned}
$$

where:
$P$ - pseudo-range between satellite and receiver;

$\Phi-$ difference between the phases of signals in the moment $\mathrm{t}$;

$\rho$ - geometric distance between satellite and receiver;

$c$ - speed of light in vacuum;

$d t$ - receiver clock offset;

$d T$ - satellite clock offset;

$d_{\text {orb }}$ - satellite orbit error

$d_{\text {trp }}$ - tropospheric delay;

$d_{\text {ion }}-$ ionospheric delay;

$\lambda$ - wavelength;

$N$ - phase ambiguity;

$\varepsilon_{P}, \varepsilon_{\Phi}$ - other code and phase dependent errors.

When precise satellite orbits and clocks are included in the processing, the ionosphere-free linear combination can be formed to remove the first order ionosphere effect. A significant drawback of this combination is, however, the increased noise of the resulting observations compared to the $\mathrm{L} 1$ and $\mathrm{C} 1$ observations (Van der Marel and Bakker, 2012). Ionosphere-free linear combination for code and phase measurements can be expressed in the following form (Cai and Gao, 2007):

$$
\begin{aligned}
& P_{I F}=\frac{P_{1} f_{1}^{2}-P_{2} f_{2}^{2}}{f_{1}^{2}-f_{2}^{2}}=\rho+c d t+d_{t r p}+\varepsilon_{p_{I F}} \\
& \phi_{I F}=\frac{\lambda_{1} \phi_{1} f_{1}^{2}-\lambda_{2} \phi_{2} f_{2}^{2}}{f_{1}^{2}-f_{2}^{2}}=\rho+c d t+d_{t r p}+N_{I F}+\varepsilon_{\phi_{I F}}
\end{aligned}
$$

There are several methods of reducing the impact of tropospheric delay in GNSS positioning. The effect of troposphere as a non-dispersive medium cannot be eliminated by the observation combination of L1 and L2 data. The average total tropospheric delay which consists of dry and wet delays can be modeled at zenith and scaled by a mapping function to the satellite elevation (Leick, 2004):

$d_{t r o p}=d_{d r y} \cdot M_{d r y}+d_{w e t} \cdot M_{w e t}$

where $d_{d r y}$ and $d_{w e t}$ are dry and wet components in the zenith, and $M_{d r y}, M_{\text {wet }}$ are corresponding mapping functions. The hydrostatic component of the troposphere can be mitigated by a number of models like the Saastamoinen or Hopfield model. One can use these models utilizing standard atmosphere parameters 


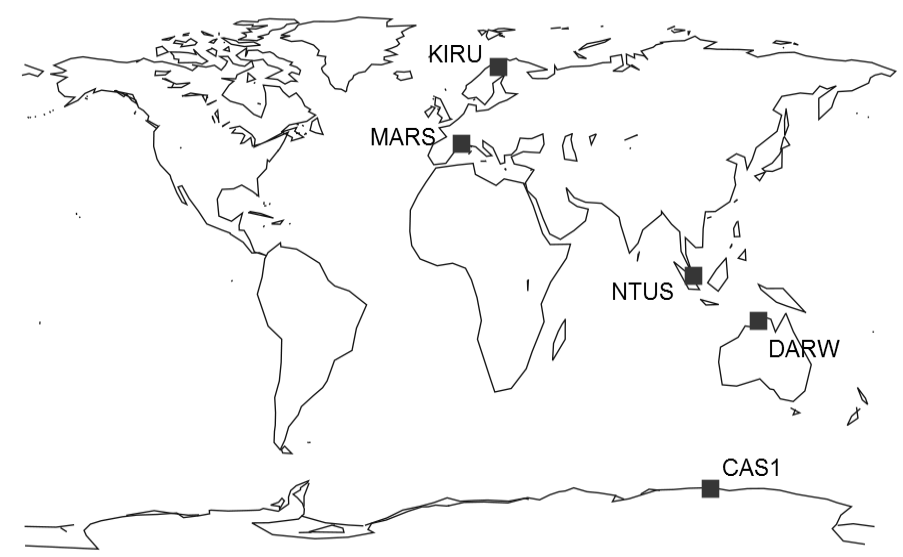

Fig. 1 Distribution of IGS stations used in research.

or by entering into model surface meteorological data from global or regional numerical meteorological models such as European Centre for Medium-Range Weather Forecast (ECMWF), the Coupled Ocean/Atmosphere Mesoscale Prediction System (COAMPS) or Global Pressure and Temperature (GPT) (Boehm et al., 2007; Kalita et al., 2014). In this article, we will describe only the Saastamoinen model, because it is used in the processing of observation using the BKG program.

The final expression for the Zenith Hydrostatic Delay, submitted in the works of Saastamoinen (1972) and Davis (1985) can be written as:

$d_{d r y}=\left(0.0022768 \pm 5 \cdot 10^{-7}\right) \cdot \frac{P_{0}}{g(\varphi, H)}$

where $P_{0}$ is the total ground pressure and $g(\varphi, H)$ is used to model the variations of acceleration due to the gravity in the function of latitude $\varphi$ and altitude $H$ of the station. Although the effect of the hydrostatic component ranges from $1.5 \mathrm{~m}$ to $2.6 \mathrm{~m}$ and represents $90 \%$ of total zenith delay (Jin et al., 2007) it can be easily modeled by determining a priori models. The wet component of tropospheric delay related to the amount of water vapor along the signal track is significantly more difficult to model (Kalita et al., 2014). It ranges from 0 to $30 \mathrm{~cm}$ and in undifferenced GNSS strategies, it can be estimated as an additional parameter during the processing. Ahmed et al. (2014) have investigated the estimated troposphere parameters using IGS-RTS and different PPP software packages.

A separate issue related to the positioning using the multi-GNSS approach are intersystem biases whose calibration is a minimum requirement of the interoperability of multiple GNSS (Wang et al., 2011; Torre and Caporali, 2014). Thus precise GNSS positioning requires some inter-system and interfrequency corrections to be included. The former involves the well-known Inter-System Bias (ISB), whereas the latter includes Differential Code Biases (DCB) and Inter-Channel Biases (ICB) (Wanninger,
2012; Chen et al., 2013a; Shi et al., 2013; Montenbruck and Hauschild, 2014; Guo et al., 2015). ISB and DCB phenomena have been widely researched in recent years. The one that causes biggest difficulties in GPS/GLONASS integration is frequency-dependent ICB. The effects of receiver ICB are different from channel-to-channel of the same receiver (Wanninger, 2012). Moreover receiver ICBs in code and carrier phase measurements are different, and for this reason are classified into code receiver ICB and carrier-phase receiver ICB, respectively (Yamada et al., 2010; Kim et al., 2013). Most of researches in this field are focused on relative positioning (Wanninger and Wallstab-Freitag, 2007; Yamada et al., 2010; Al-Shaery et al., 2013; Kim et al., 2013). However, with growing interest in the PPP further efforts have been made to estimate the influence of ICB on point positioning (Reussner and Wanninger, 2011; Chuang et al., 2013).

In addition to the PPP employing two frequencies, it is possible to process single frequency measurements (van Bree and Tiberius, 2012). However, this requires the use of different models to mitigate the influence of individual factors degrading the accuracy of positioning (in particular, the ionospheric delay), and has a significantly lower accuracy in relation to the dual-frequency approach (Dawidowicz et al., 2014).

\section{METHODOLOGY OF STUDIES}

This paper presents an analysis of the accuracy of a single GNSS receiver position determination using IGS Real-time Services and Bundesamt für Kartographie und Geodäsie (BKG) Ntrip Client (BNC) version 2.10. The BNC2.10 is an Open Source multi-stream client program designed for a variety of real-time GNSS applications provided by Federal Agency for Cartography and Geodesy. Between 22nd May and 5th June 2014 (142-156 days of year (DOY) 2014) we registered three streams of corrections: IGS01, IGS02 and IGS03. We then used these corrections to post-process the satellite observations from five randomly chosen IGS stations located at 
Table 4 IGS stations used in the processing and their parameters.

\begin{tabular}{|c|c|c|c|c|c|}
\hline & CAS1 & DARW & KIRU & MARS & NTUS \\
\hline $\mathrm{x}$ & -901776.137 & -4091359.407 & 2251420.639 & 4630532.633 & -1508023.083 \\
\hline $\mathrm{y}$ & 2409383.268 & 4684606.499 & 862817.325 & 433946.491 & 6195576.583 \\
\hline z & -5816748.495 & -1408579.454 & 5885476.803 & 4350142.829 & 148799.351 \\
\hline latitude & $66^{\circ} 17^{\prime} 0.0967 ” \mathrm{~S}$ & $12^{\circ} 50^{\prime} 37.3212^{\prime} \mathrm{S}$ & $67^{\circ} 51 ’ 26.4696 ” \mathrm{~N}$ & $\begin{array}{c}43^{\circ} 16^{\prime} 43.5756^{\prime \prime} \\
\mathrm{N}\end{array}$ & $1^{\circ} 20^{\prime} 44.8858^{\prime \prime} \mathrm{N}$ \\
\hline longitude & $\begin{array}{c}110^{\circ} 31^{\prime} 10.9425^{\prime \prime} \\
\mathrm{E}\end{array}$ & $\begin{array}{c}131^{\circ} 07^{\prime} 57.8711^{\prime \prime} \\
\mathrm{E}\end{array}$ & $20^{\circ} 58^{\prime} 6.4216^{\prime \prime} \mathrm{E}$ & $5^{\circ} 21^{\prime} 13.6417$ ' E & $103^{\circ} 40^{\prime} 47.8549^{\prime \prime} \mathrm{E}$ \\
\hline height [m] & 22.454 & 125.100 & 391.049 & 61.816 & 75.436 \\
\hline $\begin{array}{l}\text { elevation } \\
\text { cut off }\end{array}$ & $0^{\circ}$ & $0^{\circ}$ & $0^{\circ}$ & $0^{\circ}$ & $0^{\circ} *$ \\
\hline receiver & $\begin{array}{l}\text { TRIMBLE } \\
\text { NETR9 }\end{array}$ & $\begin{array}{c}\text { LEICA } \\
\text { GRX1200GGPRO }\end{array}$ & $\begin{array}{c}\text { SEPTENTRIO } \\
\text { POLARX4 }\end{array}$ & LEICA GR25 & $\begin{array}{c}\text { LEICA } \\
\text { GRX1200GGPRO }\end{array}$ \\
\hline antenna & $\begin{array}{l}\text { LEIAR25.R3 } \\
\text { LEIT } \\
\end{array}$ & $\begin{array}{c}\text { ASH700936D_M } \\
\text { NONE }\end{array}$ & $\begin{array}{c}\text { SEPCHOKE_MC } \\
\text { SPKE }\end{array}$ & $\begin{array}{l}\text { TRM57971.00 } \\
\text { NONE }\end{array}$ & $\begin{array}{c}\text { LEIAT504GG } \\
\text { NONE }\end{array}$ \\
\hline
\end{tabular}

* The value specified in the station log. The actual value obtained in the tests is $10^{\circ}$.

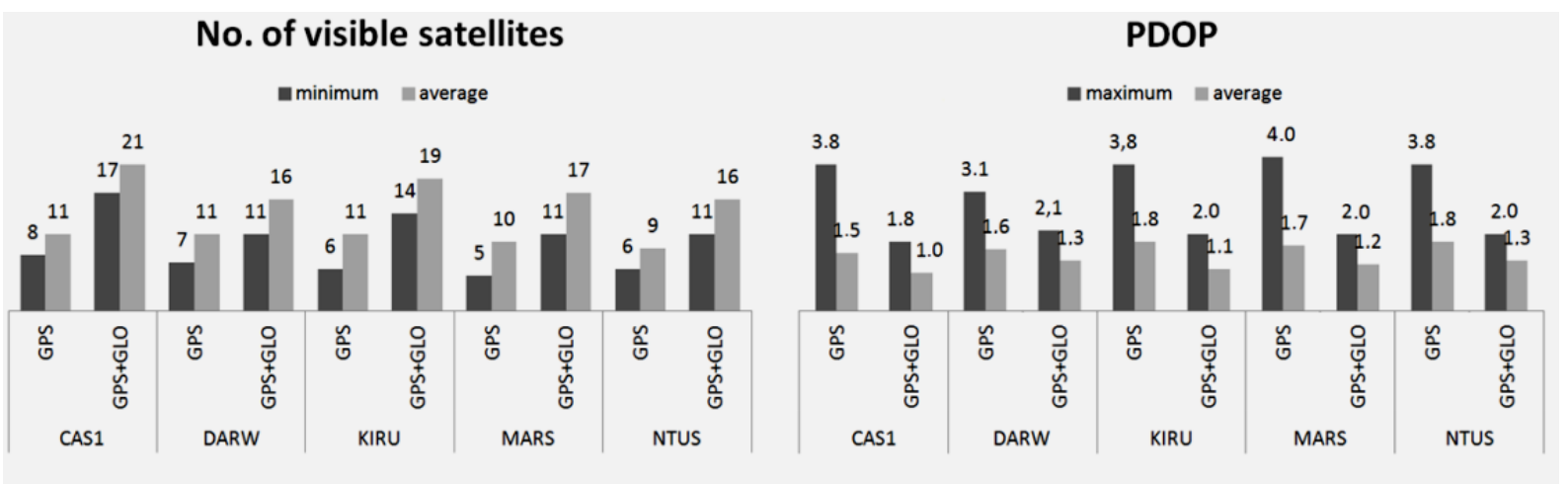

Fig. 2 Satellites visibility and PDOP values at utilized IGS stations for GPS-only and GPS+GLONASS variants.

different latitudes (Fig. 1). Table 4 contains each station's parameters.

The satellite observations were registered with a 30 seconds interval. As a reference coordinates from IGS weekly solution were adopted. In Figure 2, the satellites visibility and Position Dilution of Precision (PDOP) values at selected IGS stations are shown.

Despite the higher number of visible satellites at stations located near the pole position (CAS1 and KIRU) PDOP periodically increases with a decrease in the visibility of satellites. One reason for the relatively low number of visible satellites at NTUS turned out to be the elevation mask equal to 10 degrees (instead of 0 as defined in the station $\log$ ). Observation conditions at IGS stations can however be considered optimal in terms of unveiling the horizon, average PDOP values and applied technical solutions related to GNSS measurements, etc.

BNC2.10 applies a point positioning solution using an ionosphere-free linear combination of code and phase observations. To achieve the highest available accuracy in the study, phase observations were utilized as well as the estimation of tropospheric delay according to the equation:

$$
T(s)=T_{a p r}(s)+\frac{d T}{\cos (z)}
$$

where $T_{a p r}(s)$ is the a priori tropospheric delay derived from the Saastamoinen model. Observations were also corrected for a receiver antenna offset (using data from ANTEX file), solid earth tides and phase windup. Satellite antenna phase center offsets were not corrected because the applied orbit and clock corrections are referred to the satellite's antenna phase center. Earth rotation parameters were not required to be included in the processing, since the sub-daily ERP model is taken into account for IGS / AC orbits (Kouba, 2002). Other factors, like receiver and satellite antenna phase center variations and ocean and atmospheric loading were neglected due to the software limitations. The maximal solution gap between two consecutive solutions was set to 


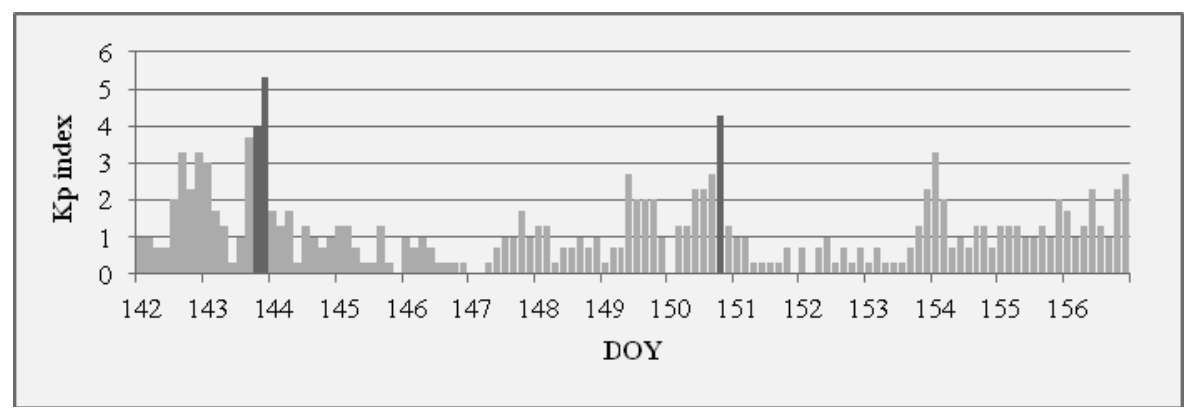

Fig. 3 Kp index during the post-processing data registration.

CAS1 IGS01

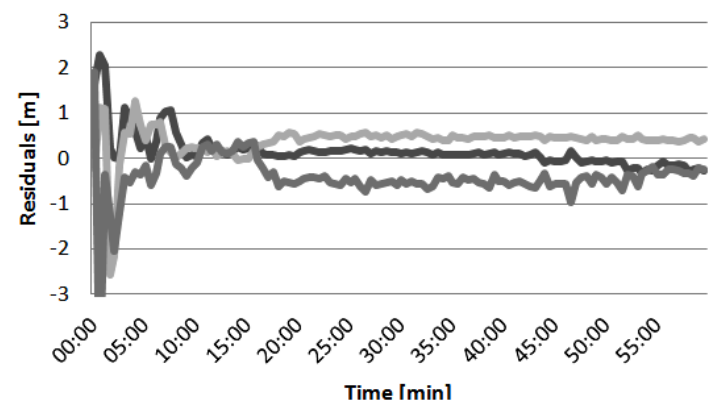

CAS1 IGS03g

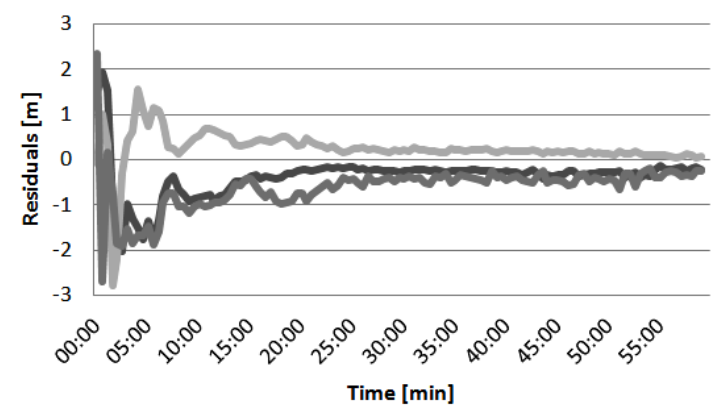

CAS1 IGS02

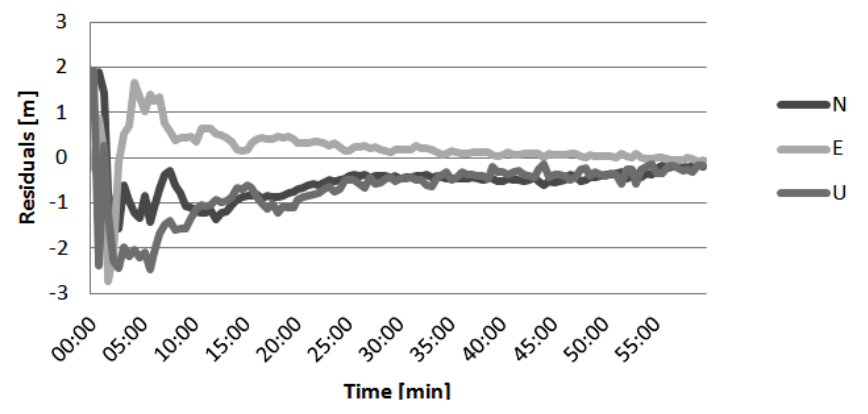

CAS1 IGS03gg

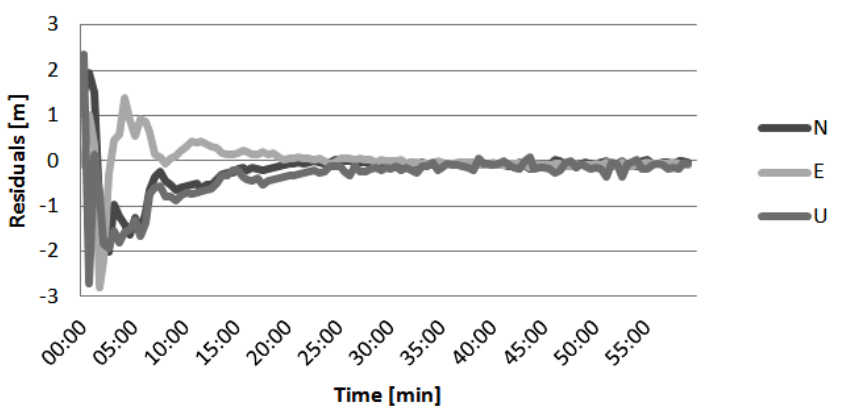

Fig. 4 Convergence time of CAS1 station observation processing.

30 minutes. If processing had exceeded this limit, software began re-designation of coordinates preceded by a period of convergence. Determination of the GNSS receiver position using IGS03 signal was performed in two variants: GPS + GLONASS (hereinafter referred to as IGS03gg) and GPS only (IGS03g), through the inclusion of the utilized system in the BNC software. Considering the nature of the message transmitted in RTCM streams (see Table 3), we would expect similar or even the same results for the variants IGS02 and IGS03g. In this processing corrections quality degradation over time was excluded, as the data were previously recorded (with the option of BNC2.10 waiting for full details) and then post-processed.

During the time of data registration the $\mathrm{Kp}$ index (Fig. 3), which is a measure of global geomagnetic activity (Bartels, 1957) and is computed every three hour was rather low, exceeding the value of 4 only three times. The $\mathrm{Kp}$ index equal to 4 indicates moderate magnetic change.

We then processed one week (6th-13th December, 2014; 340-347 DOY) of GNSS observations at the MARS using the IGS03 service for the GPS+GLONASS variant in real-time. Satellite observations were transmitted with a one second interval. In addition to the IGS corrections and observations, the $\mathrm{BKG}$ program required to utilize a RTCM3EPH stream containing the broadcast ephemeris for GPS, GLONASS. The maximal solution gap between two consecutive solutions was set to 5 minutes. In this scenario, we also set the length of the startup period (30 seconds) for which program fixed the PPP solution to a known XYZ coordinates after the loss of solution. This approach allowed long time of re-converge to be excluded from the accuracy analysis. Sample convergence time can be seen in Figure 4 which is a plot of North, East and 


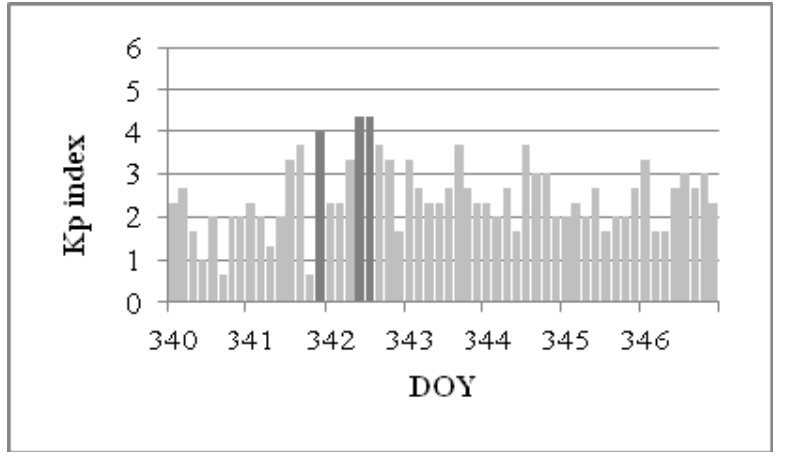

Fig. 5 Kp index during the real-time processing.
Up residuals from the CAS1 observation processing. It can be seen that the highest accuracy is reached fastest at GPS+GLONASS variant, but convergence times has not been specifically studied in this paper. The mean $\mathrm{Kp}$ index during the time of real-time processing was noticeably higher than in postprocessing scenario (Fig. 5).

\section{RESULTS}

The following graphs (Figs. 6 and 7) and tables (Tables 5 and 6) show the results of tests performed using real-time IGS corrections streams and GNSS observations of five selected IGS stations postprocessed utilizing BNC2.10. Figure 6 presents the distribution of differences between coordinates obtained in the post-processing and catalogue position derived from IGS weekly solution. Local maxima of
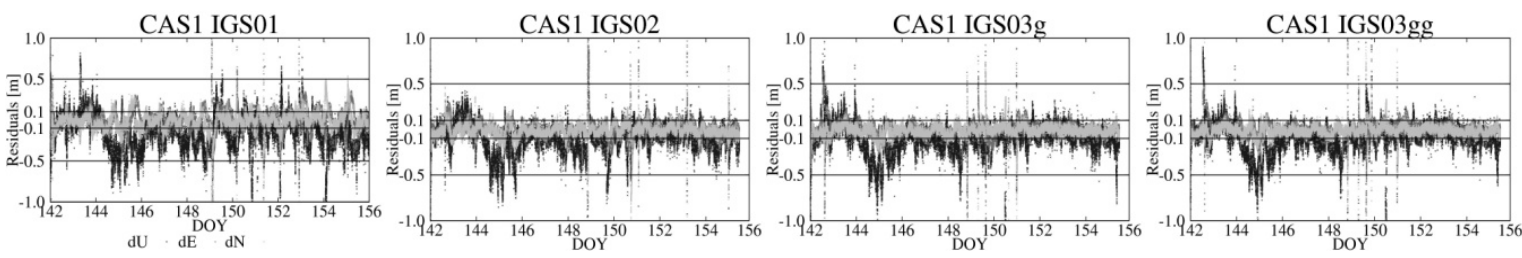

DARW IGS01
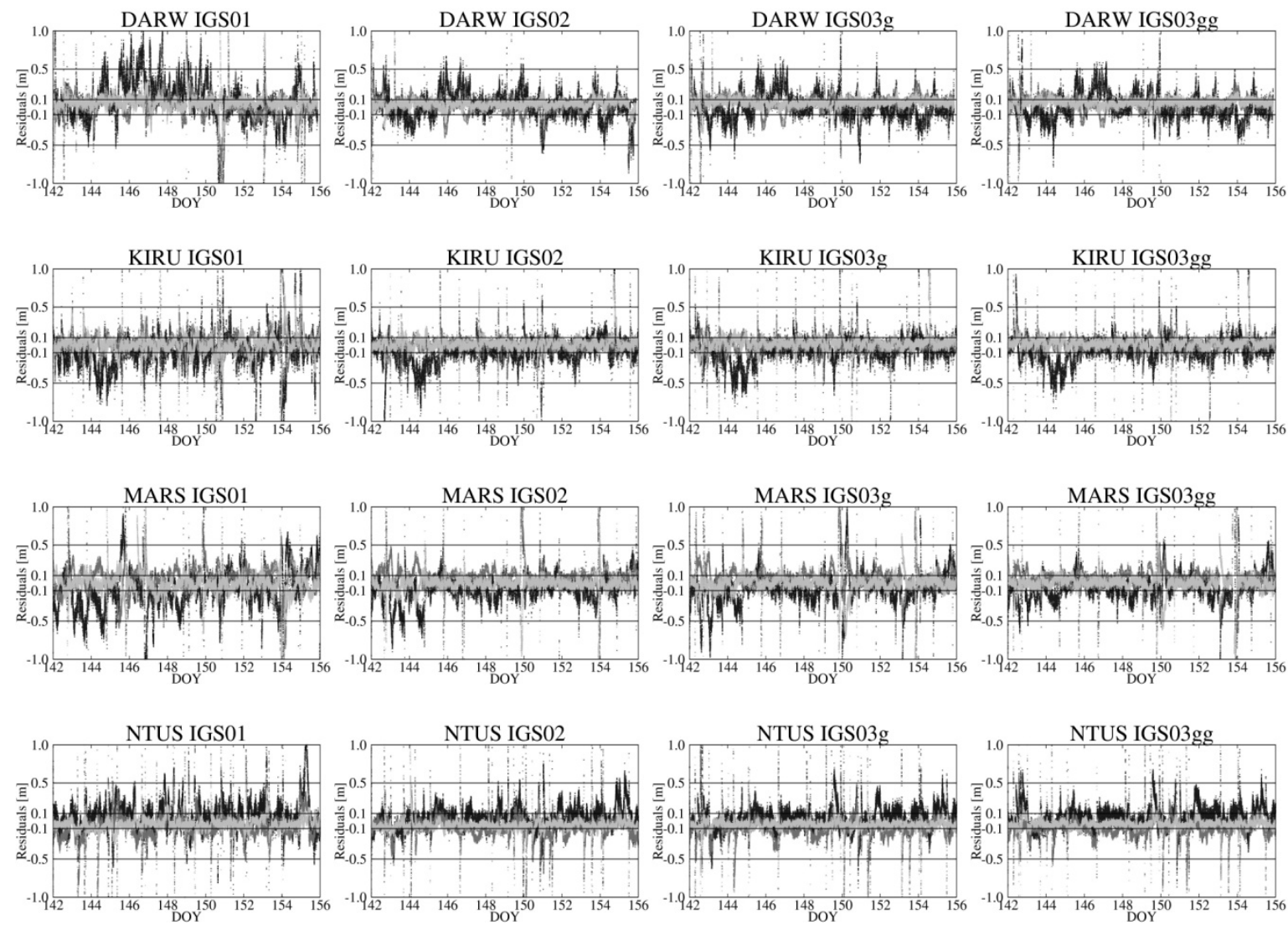

$d N \times d E \times d U \times$

Fig. 6 IGS stations coordinates residuals. 
Table 5 Percentage distribution of position residuals with respect to benchmark values.

\begin{tabular}{|c|c|c|c|c|c|c|c|c|}
\hline \multicolumn{9}{|c|}{ CAS1 } \\
\hline & \multicolumn{3}{|c|}{ IGS01 } & \multirow{2}{*}{$\begin{array}{c}\text { IGS02 } \\
\text { dU }\end{array}$} & \multicolumn{2}{|c|}{ IGS03g } & \multicolumn{2}{|c|}{ IGS03gg } \\
\hline & dH & dU & dH & & dH & dU & dH & dU \\
\hline$<1.00 \mathrm{~m}$ & $96.38 \%$ & $96.19 \%$ & $97.02 \%$ & $97.21 \%$ & $96.66 \%$ & $96.66 \%$ & $96.67 \%$ & $96.74 \%$ \\
\hline$<0.50 \mathrm{~m}$ & $95.73 \%$ & $91.64 \%$ & $96.26 \%$ & $95.00 \%$ & $95.97 \%$ & $94.12 \%$ & $96.39 \%$ & $94.48 \%$ \\
\hline$<0.20 \mathrm{~m}$ & $80.61 \%$ & $56.42 \%$ & $91.10 \%$ & $75.75 \%$ & $92.79 \%$ & $76.42 \%$ & $93.46 \%$ & $78.10 \%$ \\
\hline$<0.10 \mathrm{~m}$ & $39.17 \%$ & $31.96 \%$ & $69.59 \%$ & $47.48 \%$ & $75.06 \%$ & $48.55 \%$ & $77.71 \%$ & $51.11 \%$ \\
\hline no solution & \multicolumn{2}{|c|}{$3.28 \%$} & \multicolumn{2}{|c|}{$2.64 \%$} & \multicolumn{2}{|c|}{$2.64 \%$} & \multicolumn{2}{|c|}{$3.14 \%$} \\
\hline \multicolumn{9}{|c|}{ DARW } \\
\hline & \multicolumn{3}{|c|}{ IGS01 } & IGS02 & \multicolumn{2}{|c|}{ IGS03g } & \multicolumn{2}{|c|}{ IGS03gg } \\
\hline & dH & dU & dH & dU & dH & dU & dH & $\mathbf{d U}$ \\
\hline$<1.00 \mathrm{~m}$ & $95.29 \%$ & $94.10 \%$ & $97.11 \%$ & $97.07 \%$ & $97.04 \%$ & $96.85 \%$ & $97.05 \%$ & $96.97 \%$ \\
\hline$<0.50 \mathrm{~m}$ & $93.42 \%$ & $86.01 \%$ & $96.90 \%$ & $95.68 \%$ & $96.60 \%$ & $95.30 \%$ & $96.83 \%$ & $95.64 \%$ \\
\hline$<0.20 \mathrm{~m}$ & $82.47 \%$ & $59.77 \%$ & $89.82 \%$ & $73.72 \%$ & $90.61 \%$ & $75.85 \%$ & $91.77 \%$ & $75.37 \%$ \\
\hline$<0.10 \mathrm{~m}$ & $47.70 \%$ & $36.59 \%$ & $69.61 \%$ & $45.76 \%$ & $71.98 \%$ & $49.94 \%$ & $74.83 \%$ & $50.93 \%$ \\
\hline no solution & \multicolumn{2}{|c|}{$4.20 \%$} & \multicolumn{2}{|c|}{$2.79 \%$} & \multicolumn{2}{|c|}{$2.84 \%$} & \multicolumn{2}{|c|}{$2.83 \%$} \\
\hline
\end{tabular}

KIRU

\begin{tabular}{|c|c|c|c|c|c|c|c|c|}
\hline & \multicolumn{3}{|c|}{ IGS01 } & \multirow{2}{*}{$\begin{array}{c}\text { IGS02 } \\
\text { dU }\end{array}$} & \multicolumn{2}{|c|}{ IGS03g } & \multicolumn{2}{|c|}{ IGS03gg } \\
\hline & dH & dU & dH & & dH & dU & dH & dU \\
\hline$<1.00 \mathrm{~m}$ & $94.35 \%$ & $94.02 \%$ & $95.68 \%$ & $95.23 \%$ & $94.21 \%$ & $93.51 \%$ & $94.32 \%$ & $93.75 \%$ \\
\hline$<0.50 \mathrm{~m}$ & $91.81 \%$ & $89.60 \%$ & $94.68 \%$ & $93.04 \%$ & $93.44 \%$ & $91.88 \%$ & $93.58 \%$ & $92.40 \%$ \\
\hline$<0.20 \mathrm{~m}$ & $80.19 \%$ & $67.77 \%$ & $91.94 \%$ & $78.95 \%$ & $89.62 \%$ & $79.30 \%$ & $90.44 \%$ & $80.58 \%$ \\
\hline$<0.10 \mathrm{~m}$ & $48.96 \%$ & $41.73 \%$ & $77.77 \%$ & $54.54 \%$ & $69.53 \%$ & $56.78 \%$ & $72.11 \%$ & $57.52 \%$ \\
\hline no solution & \multicolumn{2}{|c|}{$4.18 \%$} & \multicolumn{2}{|c|}{$3.99 \%$} & \multicolumn{2}{|c|}{$5.09 \%$} & \multicolumn{2}{|c|}{$4.91 \%$} \\
\hline \multicolumn{9}{|c|}{ MARS } \\
\hline & \multicolumn{3}{|c|}{ IGS01 } & IGS02 & \multicolumn{2}{|c|}{ IGS03g } & \multicolumn{2}{|c|}{ IGS03gg } \\
\hline & dH & $\mathbf{d U}$ & dH & dU & dH & $\mathbf{d U}$ & dH & dU \\
\hline$<1.00 \mathrm{~m}$ & $95.38 \%$ & $94.80 \%$ & $94.93 \%$ & $94.76 \%$ & $93.97 \%$ & $93.53 \%$ & $94.01 \%$ & $93.73 \%$ \\
\hline$<0.50 \mathrm{~m}$ & $91.42 \%$ & $87.84 \%$ & $94.04 \%$ & $92.18 \%$ & $91.07 \%$ & $89.40 \%$ & $92.07 \%$ & $92.42 \%$ \\
\hline$<0.20 \mathrm{~m}$ & $70.02 \%$ & $58.61 \%$ & $85.18 \%$ & $77.19 \%$ & $79.26 \%$ & $71.07 \%$ & $85.06 \%$ & $77.08 \%$ \\
\hline$<0.10 \mathrm{~m}$ & $31.79 \%$ & $32.91 \%$ & $58.59 \%$ & $53.58 \%$ & $51.26 \%$ & $48.29 \%$ & $59.39 \%$ & $51.96 \%$ \\
\hline no solution & \multicolumn{2}{|c|}{$1.76 \%$} & \multicolumn{2}{|c|}{$2.27 \%$} & \multicolumn{2}{|c|}{$2.76 \%$} & \multicolumn{2}{|c|}{$2.76 \%$} \\
\hline \multicolumn{9}{|c|}{ NTUS } \\
\hline & \multicolumn{3}{|c|}{ IGS01 } & IGS02 & \multicolumn{2}{|c|}{ IGS03g } & \multicolumn{2}{|c|}{ IGS03gg } \\
\hline & dH & $\mathbf{d U}$ & dH & dU & dH & $\mathbf{d U}$ & dH & $\mathbf{d U}$ \\
\hline$<1.00 \mathrm{~m}$ & $95.38 \%$ & $94.86 \%$ & $96.05 \%$ & $96.07 \%$ & $96.01 \%$ & $95.77 \%$ & $96.07 \%$ & $95.88 \%$ \\
\hline$<0.50 \mathrm{~m}$ & $94.03 \%$ & $92.21 \%$ & $95.61 \%$ & $94.80 \%$ & $95.41 \%$ & $93.27 \%$ & $95.74 \%$ & $93.55 \%$ \\
\hline$<0.20 \mathrm{~m}$ & $84.47 \%$ & $69.63 \%$ & $91.78 \%$ & $79.39 \%$ & $87.82 \%$ & $77.04 \%$ & $88.39 \%$ & $78.10 \%$ \\
\hline$<0.10 \mathrm{~m}$ & $57.92 \%$ & $42.11 \%$ & $73.49 \%$ & $51.67 \%$ & $64.67 \%$ & $50.42 \%$ & $71.03 \%$ & $49.95 \%$ \\
\hline no solution & \multicolumn{2}{|c|}{$4.16 \%$} & \multicolumn{2}{|c|}{$3.69 \%$} & \multicolumn{2}{|c|}{$3.79 \%$} & \multicolumn{2}{|c|}{$3.77 \%$} \\
\hline
\end{tabular}


Table 6 Root Mean Square, standard deviation and mean values of residuals at each station.

\begin{tabular}{|c|c|c|c|c|c|c|c|c|c|c|c|c|}
\hline \multicolumn{13}{|c|}{ CAS1 } \\
\hline & \multicolumn{3}{|c|}{ IGS01 } & \multicolumn{3}{|c|}{ IGS02 } & \multicolumn{3}{|c|}{ IGS03g } & \multicolumn{3}{|c|}{ IGS03gg } \\
\hline & dN & $\mathrm{dE}$ & dU & $\mathbf{d N}$ & dE & dU & $d \mathbf{N}$ & $\mathrm{dE}$ & dU & $d N$ & $d E$ & dU \\
\hline RMS & 0.148 & 0.141 & 0.289 & 0.121 & 0.108 & 0.202 & 0.093 & 0.113 & 0.205 & 0.080 & 0.109 & 0.195 \\
\hline$\sigma$ & 0.147 & 0.141 & 0.244 & 0.119 & 0.108 & 0.178 & 0.092 & 0.112 & 0.178 & 0.079 & 0.108 & 0.171 \\
\hline mean & -0.014 & 0.002 & -0.155 & -0.021 & 0.005 & -0.096 & -0.013 & 0.007 & -0.102 & -0.015 & 0.009 & -0.093 \\
\hline \multicolumn{13}{|c|}{ DARW } \\
\hline & \multicolumn{3}{|c|}{ IGS01 } & \multicolumn{3}{|c|}{ IGS02 } & \multicolumn{3}{|c|}{ IGS03g } & \multicolumn{3}{|c|}{ IGS03gg } \\
\hline & $\mathbf{d N}$ & $\mathrm{dE}$ & dU & $\mathbf{d N}$ & $\mathbf{d E}$ & dU & $\mathbf{d N}$ & $\mathrm{dE}$ & dU & $d N$ & $\mathbf{d E}$ & dU \\
\hline RMS & 0.136 & 0.206 & 0.450 & 0.082 & 0.104 & 0.290 & 0.094 & 0.134 & 0.202 & 0.090 & 0.121 & 0.186 \\
\hline$\sigma$ & 0.125 & 0.206 & 0.445 & 0.074 & 0.101 & 0.290 & 0.074 & 0.118 & 0.202 & 0.071 & 0.107 & 0.185 \\
\hline mean & 0.054 & 0.011 & 0.069 & 0.035 & 0.023 & 0.020 & 0.058 & 0.064 & 0.005 & 0.055 & 0.056 & 0.012 \\
\hline \multicolumn{13}{|c|}{ KIRU } \\
\hline & \multicolumn{3}{|c|}{ IGS01 } & \multicolumn{3}{|c|}{ IGS02 } & \multicolumn{3}{|c|}{ IGS03g } & \multicolumn{3}{|c|}{ IGS03gg } \\
\hline & $\mathbf{d N}$ & $\mathbf{d E}$ & dU & $\mathbf{d N}$ & $\mathbf{d E}$ & $\mathbf{d U}$ & $d \mathbf{N}$ & $d E$ & $d U$ & $d \mathbf{N}$ & $\mathrm{dE}$ & $\mathbf{d U}$ \\
\hline RMS & 0.176 & 0.171 & 0.351 & 0.131 & 0.091 & 0.292 & 0.254 & 0.095 & 1.113 & 0.265 & 0.096 & 1.162 \\
\hline$\sigma$ & 0.176 & 0.171 & 0.342 & 0.131 & 0.091 & 0.285 & 0.253 & 0.095 & 1.113 & 0.264 & 0.096 & 1.161 \\
\hline mean & -0.005 & 0.013 & -0.082 & 0.006 & -0.009 & -0.065 & 0.017 & -0.004 & 0.011 & 0.028 & -0.005 & 0.020 \\
\hline \multicolumn{13}{|c|}{ MARS } \\
\hline & \multicolumn{3}{|c|}{ IGS01 } & \multicolumn{3}{|c|}{ IGS02 } & \multicolumn{3}{|c|}{ IGS03g } & \multicolumn{3}{|c|}{ IGS03gg } \\
\hline & $\mathbf{d N}$ & $\mathrm{dE}$ & $\mathbf{d U}$ & dN & $\mathbf{d E}$ & dU & $d \mathbf{N}$ & $\mathrm{dE}$ & dU & $d N$ & $\mathrm{dE}$ & dU \\
\hline RMS & 0.475 & 0.246 & 1.645 & 0.434 & 0.462 & 1.600 & 0.437 & 0.445 & 1.688 & 0.451 & 0.512 & 2.735 \\
\hline$\sigma$ & 0.472 & 0.243 & 1.644 & 0.432 & 0.461 & 1.599 & 0.436 & 0.445 & 1.684 & 0.450 & 0.507 & 2.735 \\
\hline mean & -0.046 & 0.040 & -0.051 & -0.041 & 0.032 & -0.047 & -0.019 & 0.020 & -0.105 & -0.019 & 0.070 & -0.036 \\
\hline \multicolumn{13}{|c|}{ NTUS } \\
\hline & \multicolumn{3}{|c|}{ IGS01 } & \multicolumn{3}{|c|}{ IGS02 } & \multicolumn{3}{|c|}{ IGS03g } & \multicolumn{3}{|c|}{ IGS03gg } \\
\hline & $\mathbf{d N}$ & $\mathbf{d E}$ & $\mathbf{d U}$ & $\mathbf{d N}$ & $d E$ & $\mathbf{d U}$ & $\mathbf{d N}$ & $d E$ & $\mathbf{d U}$ & $\mathbf{d N}$ & $\mathbf{d E}$ & $\mathbf{d U}$ \\
\hline RMS & 0.092 & 0.224 & 0.358 & 0.081 & 0.191 & 0.297 & 0.086 & 0.191 & 0.299 & 0.081 & 0.185 & 0.295 \\
\hline$\sigma$ & 0.091 & 0.224 & 0.344 & 0.080 & 0.191 & 0.282 & 0.086 & 0.191 & 0.279 & 0.081 & 0.185 & 0.277 \\
\hline mean & 0.011 & -0.013 & 0.102 & -0.012 & -0.003 & 0.093 & 0.004 & -0.011 & 0.108 & 0.005 & -0.007 & 0.102 \\
\hline
\end{tabular}

the following charts show the significant deviation from the reference position, which means the loss of solution and re-converge of coordinates. This occurrence is especially evident in the processing of IGS01 at all processed sites due to the single-epoch character of this data stream. In the study of other IGS streams the loss of solution definitely occurs less frequently, which is also reflected in the achieved accuracy of the results. During periods of increased geomagnetic activity (Kp index above 4, DOY 144 and 151) the occurrence of local maxima in the residual charts can also be seen, what is probably caused by cycle slips in observations. According to the predictions the vertical component of coordinates is characterized by the largest offsets from the reference value. In the case of the horizontal components, it can be seen that most of the residuals are contained in the range of $\pm 0.20 \mathrm{~m}$ to the reference position (70.02\% $\% 93.46 \%$ depending on the variant).
In Table 5 the percentage distribution of the determined position residuals $(\mathrm{dH}-$ horizontal residuals, $\mathrm{dU}$ - vertical residuals) from the catalogue values are shown. During the two-week GNSS observation period the lack of solution exceeded $5 \%$ of all observations only at KIRU for processing utilizing the IGS03 data stream (GPS-only strategy). Processing of IGS02 and IGS03g variants for most of the selected stations is characterized by the similar number of solved epochs, but the resulting accuracy is slightly different.

IGS02, IGS03g and IGS03gg solutions achieved a similar, very high accuracy of horizontal coordinates. Excluding MARS residuals from these solutions did not exceed 0.2 in nearly $90 \%$ of processed epochs. At the same time the use of GLONASS signals in processing did not result in significant improvement of the accuracy. The reasons for this may be the optimal horizon visibility at IGS stations, difficulties in combined GPS/GLONASS 


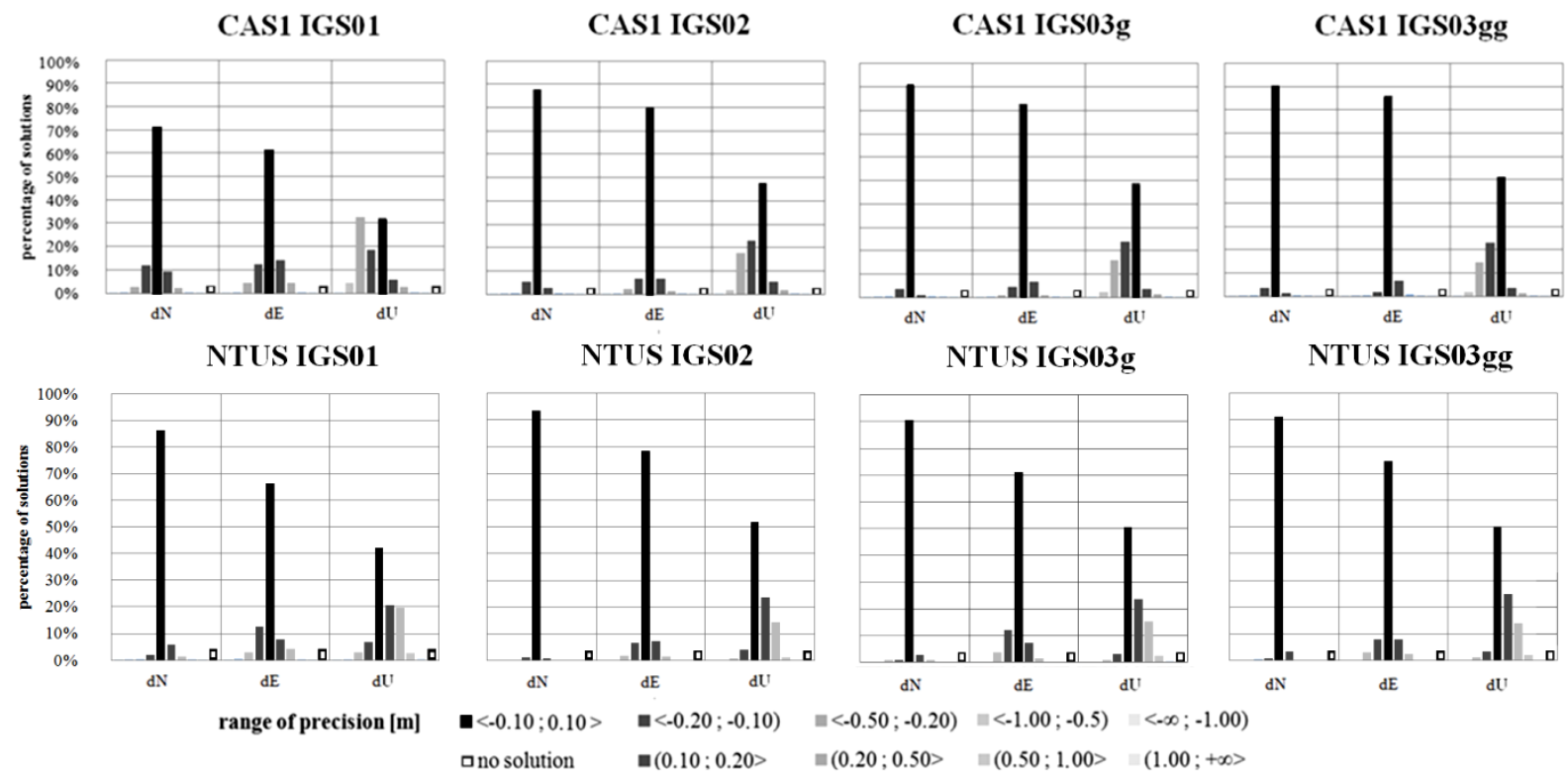

Fig. 7 Probability of achieving results within the assumed ranges of accuracy.

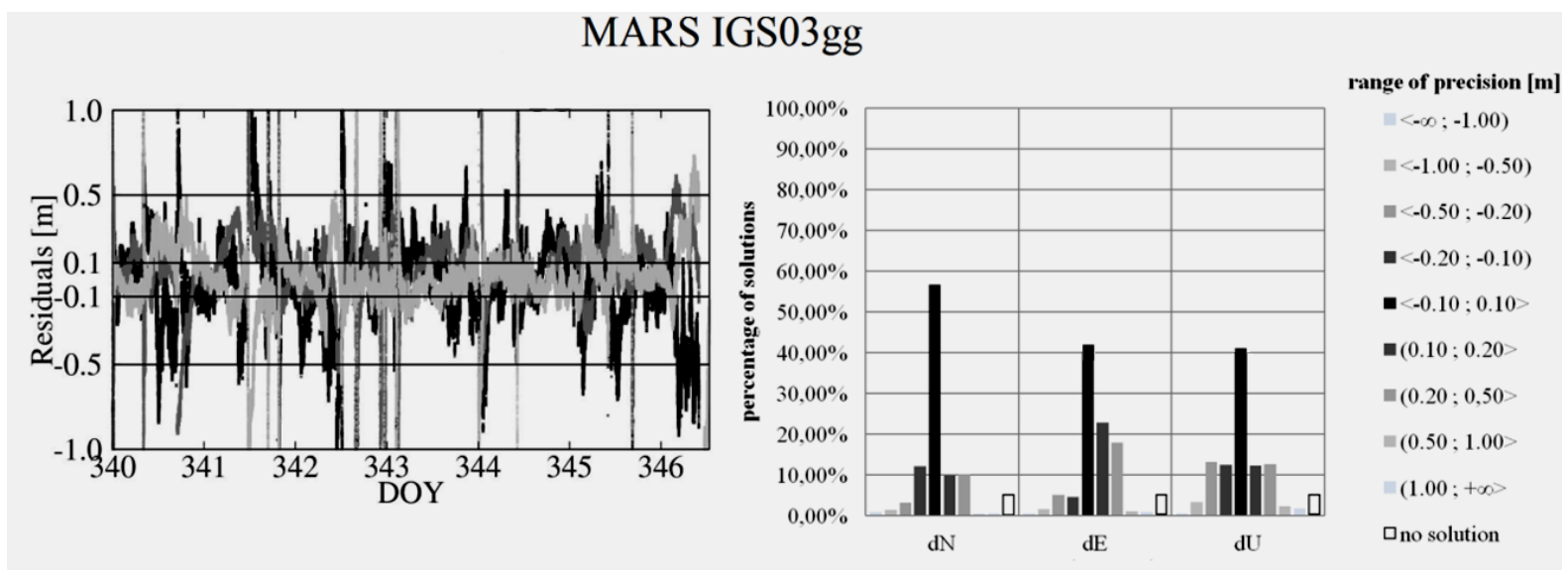

Fig. 8 MARS station coordinates residuals and histograms.

positioning and the experimental nature of the IGS03 data stream. We can anticipate that the use of the IGS03 stream in conditions of limited satellite visibility may contribute to improvement of the achieved results, but this issue requires further research. Considering the results given in Table 6 , low mean values, as well as similar root mean squares (RMS) and standard deviations $(\sigma)$ for each station can be seen. It means that the processing is not affected by significant systematic errors. The highest residual mean values occur for height component (dU) which exceed $0.10 \mathrm{~m}$ in some cases. Significantly higher RMS and $\sigma$ values at KIRU and MARS are due to the occurrence of short periods characterized by several tens of meters errors. However, coordinates with such a low accuracy represent less than $3 \%$ of all estimates for MARS and less than $1 \%$ for KIRU.

Figure 7 shows the probability of achieving results within the assumed ranges of accuracy for two stations: CAS1 located in the southern polar region and NTUS located near the equator. The distorted geometry of visible satellites at the station neighboring the pole is a probable cause of weaker accuracy of the determined coordinates. This difference is particularly evident in the processing of the IGS01 stream which is a combination of singleepoch solutions. Other variants based on the streams using the Kalman filter combination resulted in much better accuracy. The particularly low accuracy of height coordinate estimation is noticeable. At CAS1 it can be seen that dU component is understated, while at NTUS situation is reversed. Nevertheless, in most cases the GNSS positioning accuracy with the use of services based on a Kalman filter combination is very high and can be further improved by reducing the loss of solutions, and thus eliminating the reconverge.

In Figure 8 and Tables 7 and 8 the results of realtime tests performed using the IGS03 correction 
Table 7 Percentage distribution of determined position residuals in real-time processing.

\begin{tabular}{|c|c|c|}
\hline \multicolumn{3}{|c|}{ MARS IGS03gg real-time } \\
\hline & dH & $\mathbf{d U}$ \\
\hline$<1.00 \mathrm{~m}$ & $97.92 \%$ & $97.86 \%$ \\
\hline$<0.50 \mathrm{~m}$ & $93.87 \%$ & $92.24 \%$ \\
\hline$<0.20 \mathrm{~m}$ & $61.83 \%$ & $66.44 \%$ \\
\hline$<0.10 \mathrm{~m}$ & $29.73 \%$ & $41.62 \%$ \\
\hline no solution & & $3 \%$ \\
\hline
\end{tabular}

stream and GNSS observations at MARS station are shown. Real-time position determination, despite similar measurement conditions, featured lower accuracy than results obtained in post-processing. The loss of solution occurred more frequently, what is reflected as numerous local maxima in the following charts. In the determination of the easting and height components only about $40 \%$ results were within $\pm 10 \mathrm{~cm}$ offset, while the accuracy of northing component was found only slightly better. A small number of unresolved epochs are the effect of setting the maximal solution gap between two consecutive solutions to 5 minutes. During the measurement, there were no internet connection interruptions. The reason for much lower accuracy in the real-time variant may be delays in the transmission of corrections via the Internet to $\mathrm{BNC} 2.10$ and the higher geomagnetic activity during the processing (see Figs. 3 and 5).

\section{SUMMARY AND CONCLUSIONS}

The study investigated the possibility of using real-time IGS services in precise GNSS positioning. Three IGS-RTS streams were tested: IGS01, IGS02 and IGS03 in two variants (GPS only and GPS+GLONASS). Using BNC2.10 two weeks of data for each of the services were recorded and the raw observations from five IGS stations (KIRU, MARS, NTUS, DARW and CAS1) spread between ca. $68^{\circ} \mathrm{N}$ to $66^{\circ} \mathrm{S}$ latitude were then post-processed. This procedure produced more than 800,000 threedimensional positions that were analyzed. For all stations the lowest accuracy was characterized by the IGS01 variant. Especially in the determination of the height component, where only $31.96 \%$ to $42.11 \%$ results were within $\pm 10 \mathrm{~cm}$, probably due to "the single-epoch nature" of the IGS01 data stream. Significantly better results were found for IGS02 service processing which is based on a Kalman filter combination. Despite the identical broadcast messages and the application of a Kalman filter to determine the adjustments, there were differences between the results for position determination using IGS02 and IGS03 in GPS mode. The reason for this may be the difference in each stream generation time. Adding GLONASS signals to processing (IGS03gg variant) in
Table 8 Root Mean Square, standard deviation and mean values of residuals at MARS station in real-time processing.

\begin{tabular}{cccc}
\hline \multicolumn{4}{c}{ MARS IGS03gg real-time } \\
\hline RMS & $\mathbf{d N}$ & $\mathbf{d E}$ & $\mathbf{d U}$ \\
$\boldsymbol{\sigma}$ & 0.843 & 0.575 & 1.917 \\
mean & -0.842 & 0.509 & 1.914 \\
\hline
\end{tabular}

most cases did not resulted in significant improvement. Further advantages of the two satellite navigation systems also probably arise in the case of positioning in difficult observation conditions, but this requires verification in the course of further research. Results of post-processing were verified by measurements made in real-time. For this purpose BNC2.10 was used and the data transmitted by the IGS: broadcast ephemeris, raw observations from the station MARS and IGS03 (GPS/GLONASS) corrections stream were utilized. Real-time position determination did not confirmed the results obtained in post-processing and featured significantly lower accuracy, which is probably due to delays in the transmission of corrections via the Internet to BNC2.10 and the higher geomagnetic activity during the processing.

The results of tests presented in the article predispose PPP using IGS-RTS corrections for use in the surveying work requiring less accuracy (e.g. GIS measurements), control of measurements made by other methods or GNSS measurements in areas where there are lack of continuously operating reference stations (CORS). Differences from the normally used standard deviation and RMS (Root Mean Square) approach showing the achievable accuracy thresholds allows the estimation of potential applications, depending on the expected accuracy of positioning. Invariably, the biggest limitation in the usage of the PPP on a large scale is the convergence time, which is indispensable to achieve the highest accuracy. We also must be aware that due to certain limitations of BNC2.10, as described in the text, achieving the maximum potential IGS-RTS PPP was not possible. Nevertheless, the results presented in this study indicate the high potential of this positioning strategy, along with its further development.

\section{REFERENCES}

Ahmed, F., Václavović, P., Teferle, F.N., Douša, J., Bingley, R. and Laurichesse, D.: 2014, Comparative analysis of real-time precise point positioning zenith total delay estimates. GPS Solutions. DOI: $10.1007 / \mathrm{s} 10291-014-0427-\mathrm{Z}$

Al-Shaery, A., Zhang, S. and Rizos, C.: 2013, An enhanced calibration method of GLONASS inter-channel bias 
for GNSS RTK. GPS Solutions, 17, No. 2, $165-173$. DOI: 10.1007/s10291-012-0269-5

Bakuła, M.: 2013, Study of reliable rapid and ultrarapid static GNSS surveying for determination of the coordinates of control points in obstructed conditions. Journal of Surveying Engineering, 139, No. 4, 188 193. DOI: 10.1061/(ASCE)SU.1943-5428.0000109

Bakuła, M., Przestrzelski, P. and Kaźmierczak, R.: 2015, Reliable technology of centimeter GPS/GLONASS surveying in forest environments. IEEE Transactions on Geoscience and Remote Sensing, 53, No. 2, 1029 1038. DOI: $10.1109 /$ TGRS.2014.2332372

Bartels, J.: 1957, The technique of scaling indices K and Q of geomagnetic activity. Ann Intern Geophys., 1, 4, 215-226.

Baryła, R., Paziewski, J., Wielgosz, P., Stępniak, K. and Krukowska, M.: 2014, Accuracy assessment of the ground deformation monitoring with the use of GPS local network: Open pit mine Koźmin Case Study. Acta Geodyn. Geomater., 11, No. 4, 317-324. DOI: $10.13168 /$ AGG.2014.0013

Boehm, J., Heinkelmann, R. and Schuh, H.: 2007, Short note: a global model of pressure and temperature for geodetic applications. Journal of Geodesy, 81, No. 10, 679 -683. DOI: 10.1007/s00190-007-0135-3

Cai, Ch. and Gao, Y.: 2007, Precise Point Positioning using combined GPS and GLONASS observations. Journal of Global Positioning System., 6, No. 1, $13-22$.

Cai, Ch. and Gao, Y.: 2013, GLONASS-based precise point positioning and performance analysis. Advances in Space Research., 51, No. 3, 514-524. DOI: $10.1016 /$ j.asr.2012.08.004

Chen J., Ge M., Douša J. and Gendt, G., 2009. Evaluation of EPOS-RT for real-time deformation monitoring. Journal of Global Positioning Systems, 8, No. 1, 1-5.

Chen, J., Xiao, P., Zhang, Y. and Wu, B.: 2013a, GPS/GLONASS system bias estimation and application in GPS/GLONASS combined positioning. China Satellite Navigation Conference (CSNC) 2013 Proceedings. Lecture Notes in Electrical Engineering, 244, 323 -333. DOI: 10.1007/978-3-642-37404-3 29

Chen, J., Li, H., Wu, B., Zhang Y., Wang, J. and Hü, C.: 2013b, Performance of real-time precise point positioning. Marine Geodesy, 36, No. 1, $98-108$. DOI: $10.1080 / 01490419.2012 .699503$

Chuang, S., Wenting, Y., Weiwei, S., Yidong, L., Yibin, Y. and Rui, A.: 2013, GLONASS pseudorange interchannel biases and their effects on combined GPS/GLONASS precise point positioning. GPS Solutions, 17, No. 4, 439-451. DOI: 10.1007/s10291-013-0332-x

Collins, P.: 2008, Isolating and estimating undifferenced GPS integer ambiguities. Proceedings of ION national technical meeting. San Diego, US, 720-732.

Davis, J. L., Herring, T. A., Shapiro, I. I., Rogers, A.E.E. and Elgered, G.: 1985, Geodesy by radio interferometry: effects of atmospheric modelling errors on estimates of baseline length. Radio Science, 20, No. 6, 1593-1607. DOI: 10.1029/RS020i006p01593

Dawidowicz, K. and Krzan, G.: 2014, Coordinate estimation accuracy of static precise point positioning using online PPP service- a case study. Acta Geodaetica et Geophysica Hungarica, 49, No. 1, 37-55.

DOI: $10.1007 / \mathrm{s} 40328-013-0038-0$

Defraigne, P., Bruyninx, C. and Guyennon, N.: 2007, PPP and phase-only GPS time and frequency transfer. Proceedings of the IEEE International Frequency
Control Symposium. Joint with the 21st European Frequency and Time Forum, Geneva, 904 -908.

Douša, J. and Vaclavović, P.: 2014, Real-time zenith tropospheric delays in support of numerical weather prediction applications. Adv Space Res., 53, No. 9, 1347-1358. DOI: 10.1016/j.asr.2014.02.021

Elsobeiey M. and Al-Harbi S., 2015. Performance of realtime Precise Point Positioning using IGS real-time service. GPS Solutions. DOI: 10.1007/s10291-0150467-z

Ge, M., Gendt, G., Rothacher, M., Shi, C. and Liu, J.: 2008, Resolution of GPS carrier-phase ambiguities in precise point positioning (PPP) with daily observations. Journal of Geodesy, 8, No. 7, 389 -399. DOI: 10.1007/s00190-007-0187-4

Guo, F., Zhang, X.H. and Wang, J.: 2015, Timing group delay and differential code bias corrections for BeiDou positioning. Journal of Geodesy, 89, No. 5, 427 -445. DOI: 10.1007/s00190-015-0788-2

Hadaś, T. and Bosy, J.: 2014, IGS RTS precise orbits and clocks verification and quality degradation over time. GPS Solutions, 19, No. 1, 93 -105. DOI: 10.1007/s10291-014-0369-5

Jin, S., Park, J.U., Cho, J.H. and Park, P.H.: 2007, Seasonal variability of GPS-derived zenith tropospheric delay (1994-2006) and climate implications. Journal of Geophysical Research, 112(D9). DOI: 10.1029/2006JD007772

Juan, J.M., Hernandez-Pajares, M., Sanz, J., Ramos-Bosch, P., Aragon-Angel, A., Orus, R., Ochieng, W., Feng, S., Jofre, M., Coutinho, P. and Tossaint, M.: 2012, Enhanced Precise Point Positioning for GNSS users. IEEE Transactions on Geoscience and Remote Sensing, 50, No. 10, 4213-4222. DOI: $10.1109 /$ TGRS.2012.2189888

Kalita, J., Rzepecka, Z. and Krzan, G., 2014. Evaluation of the possibility of using the predicted tropospheric delays in real time GNSS positioning. Artificial Satellites, 49, No. 4, 179-189. DOI: $10.2478 /$ arsa-2014-0014

Kim, H.S., Lee, J.Y., Choi, K.H., Heo, M.B. and Lee, H.K.: 2013, Receiver inter-channel bias search technique based on LAMBDA. Proceedings of IGNSS Symposium, Gold Coast, July 16-18 2013.

Kouba, J.: 2002, Sub-daily Earth rotation parameters and the International GPS Service Orbit/Clock Solution products. Studia Geophysica et Geodetica, 46, No. 1, 9 -25. DOI: 10.1023/A:1019894614643

Kouba, J.: 2009, A Guide to using International GNSS Service (IGS) Products. Geodetic Survey Division. Natural Resources Canada. (online at: http://igscb.jpl.nasa.gov/igscb/resource/pubs/UsingIG SProductsVer21.pdf)

Laurichesse, D.: 2011, The CNES Real-time PPP with undifferenced integer ambiguity resolution demonstrator. 11. Proceedings of the ION GNSS 2011, Portland. Oregon, 654-662.

Leandro, R.F., Santos, M.C. and Langley, R.B.: 2011, Analyzing GNSS data in precise point positioning software. GPS Solutions, 15, No. 1, 1-13. DOI: 10.1007/s10291-010-0173-9

Leick, A.: 2004, GPS Satellite surveying. John Wiley\&Sons. New Jersey.

Li, P. and Zhang, X.: 2014, Integrating GPS and GLONASS to accelerate convergence and initialization times of precise point positioning. GPS Solutions, 18, No. 3, 461-471. DOI: 10.1007/s10291-013-0345-5 
Li, X., Ge, M., Dai, X., Ren, X., Fritsche, M., Wickert, J. and Schuh, H.: 2015, Accuracy and reliability of multi-GNSS real-time precise positioning: GPS, GLONASS, BeiDou, and Galileo. Journal of Geodesy, 89, No. 6, 607-635. DOI: $10.1007 / \mathrm{s} 00190-015-0802-8$

Li, X., Ge, M., Lu, C., Zhang, Y., Wang, R., Wickert, J. and Schuh, H.: 2014, High-rate GPS seismology using real-time precise point positioning with ambiguity resolution. IEEE Transactions on Geoscience and Remote Sensing, 52, No. 10, 6165-6180. DOI:10.1109/TGRS.2013.2295373

Li, X., Ge, M., Zhang, H., Nischan, T. and Wickert J.: 2013, The GFZ real-time GNSS precise positioning service system and its adaption for COMPASS. Advances in Space Research, 51, No. 6, 1008-1018. DOI: $10.1016 /$ j.asr.2012.06.025

Misra, P. and Enge, P.: 2011, Global Positioning System: Signals. Measurements. and Performance. Revised Second Edition. Ganga-Jamuna Press. Lincoln, Massachusetts.

Montenbruck, O. and Hauschild, A.: 2014, Differential code bias estimation using Multi-GNSS observations and Global Ionosphere Maps. Proceedings of the IONITM 2014, San Diego, 802-812.

Reussner, N. and Wanninger, L.: 2011, GLONASS interfrequency biases and their effects on RTK and PPP carrier-phase ambiguity resolution. Proceedings of the ION GNSS 2011, Portland, Oregon, $712-716$.

Saastamoinen, J.: 1972, Atmospheric correction for troposphere and stratosphere in radio ranging of satellites. The Use of Artificial Satellites for Geodesy. Geophysical Monograph, 15, 247-252. DOI: $10.1029 / \mathrm{GM} 015 \mathrm{p} 0247$

Salazar, D., Hernandez-Pajares, M., Juan, J. M. and Sanz, J.: 2010, GNSS data management and processing with the GPSTk. GPS Solutions, 14, No. 3, 293-299. DOI: 10.1007/s10291-009-0149-9

Shi, Ch., Yi, W., Song, W., Lou, Y., Yao, Y. and Zhang, R.: 2013, GLONASS pseudorange inter-channel biases and their effects on combined GPS/GLONASS precise point positioning. GPS Solutions, 17, No. 4, 439-451. DOI: 10.1007/s10291-013-0332-x

Shi, J., Xu, C., Li, Y. and Gao, Y.: 2015, Impacts of realtime satellite clock errors on GPS precise point positioning-based troposphere zenith delay estimation. Journal of Geodesy.

DOI: 10.1007/s00190-015-0811-7

Torre, A.D. and Caporali, A.: 2014, An analysis of intersystem biases for multi-GNSS positioning. GPS Solutions, 19, No. 2, 297-307. DOI: $10.1007 / \mathrm{s} 10291-014-0388-2$
Van Bree, R. J. P. and Tiberius, Ch. C. J. M.: 2012, Realtime single-frequency precise point positioning: accuracy assessment. GPS Solutions, 16, No. 2, 259266. DOI: $10.1007 / \mathrm{s} 10291-011-0228-6$

Van Der Marel, H. and De Bakker, P.: 2012, Single versus Dual-Frequency Precise Point Positioning. What are the tradeoffs between using L1-only and $\mathrm{L} 1+12$ for PPP? Inside GNSS, 7, No. 4, 30-35.

Van Dam, T.M., Blewitt, G. and Heflin, M.B.: 1994, Atmospheric pressure loading effects on Global Positioning System coordinate determinations. Journal of Geophysical Research, 99, B12, 2393923950. DOI: $10.1029 / 94 J B 02122$

Wang, J., Knight, N.L. and Lu, X.: 2011, Impact of the GNSS time offsets on positioning reliability. Journal of Global Positioning System, 10, No. 2, 165-172. DOI: 10.5081/jgps.10.2.165

Wanninger, L.: 2012, Carrier-phase inter-frequency biases of GLONASS receivers. Journal of Geodesy, 86, No. 2, 139-148. DOI: 10.1007/s00190-011-0502-y

Wanninger, L. and Wallstab-Freitag, S.: 2007, Combined processing of GPS, GLONASS and SBAS code phase and carrier phase measurements. Proceedings of ION GNSS 2007, Fort Worth, Tx., 866-875.

Wielgosz, P., Krukowska, M., Paziewski, J., KrypiakGregorczyk, A., Stępniak, K., Kapłon, J., Sierny, J., Hadaś, T. and Bosy, J.: 2013, Performance of ZTD models derived in near real-time from GBAS and meteorological data in GPS fast-static positioning. Measurement Science and Technology, 24, No. 12 DOI:10.1088/0957-0233/24/12/125802.

Yamada, H., Takasu, T., Kubo, N. and Yasuda, A.: 2010, Evaluation and calibration of receiver inter-channel biases for RTK-GPS/GLONASS. Proceedings of 23rd International Technical Meeting of the Satellite Division of the Institute of Navigation, Portland, 1580-1587.

Zumberge, J.F., Heflin, M.B., Jefferson, D.C., Watkins, M.M. and Webb, F.H.: 1997, Precise Point Positioning for the efficient and robust analysis of GPS data from large networks. Journal of Geophysic Research, 102, B3, 5005-5017. DOI: 10.1029/96JB03860 